\title{
EFEITOS DO TRATAMENTO DE RESÍDUOS SÓLIDOS NA SAÚDE E NA ECONOMIA
}

\author{
Regina Duarte ${ }^{1}$ \\ Richardson Miranda Machado ${ }^{2}$
}

DUARTE, R.; MACHADO, R. M. Efeitos do tratamento de resíduos sólidos na saúde e na economia Arq. Ciênc. Saúde UNIPAR, Umuarama, v. 19, n. 2, p. 159-161, maio/ago. 2015.

\begin{abstract}
RESUMO: Com esse estudo bibliográfico objetivou-se discorrer a respeito dos efeitos do tratamento de resíduos sólidos e seu impacto na saúde e na economia, com destaque para a gestão pública tanto do Sistema Único de Saúde, como do meio ambiente. Para tanto, foi realizada análise de legislações que legitimam e regulam a destinação de resíduos sólidos, popularmente chamado de lixo, bem como literaturas pertinentes. O estudo chama atenção para a necessidade de implementação de estratégias que possam corroborar com a qualidade de vida da população, a partir da adequada destinação dos resíduos sólidos urbanos. Recomenda-se a adoção da educação ambiental, em especial nos currículos desde o ensino fundamental e médio, abarcando também o ensino superior, visto que as profissões da área da saúde utilizam a educação em saúde como ferramenta para promoção da saúde.
\end{abstract}

PALAVRAS-CHAVE: Meio ambiente; Resíduos sólidos; Educação ambiental.

\section{EFFECTS OF SOLID WASTE TREATMENT IN HEALTH AND ECONOMY}

\begin{abstract}
This bibliographical study aimed to discuss the effects of treating solid waste and its impact on health and the economy, emphasizing the governance of both the Unified Health System, as the environment. Legislation analysis was performed on the laws that legitimize and regulate the disposal of solid waste, popularly called garbage, as well as relevant literature. The study calls attention to the need of implementing strategies that can corroborate to the quality of life of the population from the proper disposal of solid waste. The adoption of environmental education, particularly in the curricula from elementary and secondary education is recommended, as well as in higher education, since the health care professions use health education as a tool for promoting health.
\end{abstract}

KEYWORDS: Environment; Solid Waste; Environmental Education.

\section{Introdução}

A destinação dos resíduos sólidos urbanos, cada vez mais crescente em decorrência do consumo de produtos consumidos pela população em geral e a escassez de educação ambiental, tem se tornado problema de saúde pública, haja vista que nem todos os municípios possuem unidade de tratamento de resíduos sólidos (UTR), o que resolveria a situação precária provocada por lixões a céu aberto (JACOB et al, 2011) e a educação ambiental ainda não integra os currículos de formação desde o nível fundamental ao superior.

De acordo com a Associação Brasileira das Empresas de Limpeza Pública e Resíduos Especiais (ABRELPE, 2011), em 2011 a quantidade média diária de resíduos sólidos chegou a 198.514 toneladas. Desse total, 177.995 toneladas foram coletadas, sendo 58,1\% destinados aos aterros sanitários, outros $24,2 \%$ para aterros controlados e $17,7 \%$ para lixões a céu aberto. De acordo com os dados, restam 20.519 toneladas que não são sequer coletadas. Se forem somados este número ao volume que destinou-se aos aterros controlados e lixões, têm-se cerca de $50 \%$ dos resíduos gerados diariamente em todo o país que, na maioria das vezes, estão sendo destinado a locais impróprios e ocasiona todo tipo de poluição, visível ou não, inclusive causando sérios danos à saúde humana, além de desequilíbrio do meio ambiente.

Ressalta-se que a ABRELPE (2011) mencionou apenas os rejeitos oriundos dos resíduos sólidos urbanos que, na atualidade, constituem-se em problema enfrentado pela maioria dos municípios em todo o país. Assim, acredita-se que havendo investimentos em UTR, além de atender as necessidades de tratamento dos resíduos sólidos, podem levar a lucros a partir da geração de energia. Portanto, é oportuno a realização de estudos que possam apontar os benefícios propiciados pela destinação adequada dos resíduos sólidos urbanos, como a geração de energia e a preservação do meio ambiente.

Em relação ao meio ambiente ecologicamente saudável, a Constituição da República Federativa do Brasil (BRASIL, 1988), assegura no Artigo 225 que todos os cidadãos brasileiros possuem o direito ao meio ambiente ecologicamente equilibrado, logo, constitui-se em responsabilidade do setor público, prover meio ambiente saudável, embora todo cidadão tenha responsabilidade na preservação do meio ambiente.

Ainda em relação a base legal, à Lei Federal $n^{\circ}$ 12.305 (BRASIL, 2010), que instituiu a Política Nacional de Resíduos Sólidos, chama atenção no Artigo $9^{\circ}$ que "na gestão e gerenciamento de resíduos sólidos, deve ser observada a seguinte ordem de prioridade: não geração, redução, reutilização, reciclagem, tratamento dos resíduos sólidos e disposição final ambientalmente adequada dos rejeitos". Referida Lei deixa claro a responsabilidade dos municípios em destinar e dispor adequadamente seus resíduos sólidos.

O resíduo sólido urbano, popularmente chamado de lixo, pode ser considerado como uma das causas que levam a crise ambiental e a tecnologia ambiental constitui-se em meio para reverter a situação. O termo "lixo" perdeu significado no mundo acadêmico e jurídico sendo substituído pela denominação resíduo, devido ser passível de tratamento e/ou reaproveitamento, ao que se deve ser encaminhado ao processo de reciclagem e disposição final, inclusive com potencial de gerar lucros financeiros, como ocorre em locais onde 
se tem a produção de energia a partir dos resíduos sólidos urbanos (VOLOCH, 2012).

A necessidade de energia elétrica no mundo cresce na mesma proporção que cresce o volume de resíduo sólido urbano. Harmonizar de modo operacional as curvas de crescimento constitui um dos grandes desafios tecnológicos na atualidade. Essa é a razão pela qual vem crescendo rapidamente o número de países que investem no aproveitamento energético com origem de resíduo sólido urbano (ABRELPE, 2011).

No Brasil não há usina de tratamento de resíduos que utiliza os rejeitos como subproduto transformando em fonte de energia elétrica usando o sistema de carbonização contínua que pode ser uma alternativa econômica à saúde humana e ao meio ambiente, já que o maior causador de doenças sanitárias e impacto negativo ao meio ambiente são os constante lixões existentes na maioria dos municípios.

Para Voloch (2012), a possibilidade de aproveitamento energético dos resíduos abre uma nova perspectiva de destinação diferente dos tradicionais aterros sanitários e as tecnologias denominadas WTE do termo em inglês "waste-to-energy" ou "energia a partir do lixo", apesar de pouco difundida no Brasil, são muito utilizadas em países desenvolvidos.

Em Mato Grosso do Sul, dos municípios que possuem UTR, nenhum deles implantou o sistema de carbonização para geração de energia a partir do resíduo sólido urbano. Portanto, há necessidade premente dos governantes adotarem modelos de outras localidades que beneficiam a saúde da população e geram recursos públicos, a partir dos resíduos sólidos. Acredita-se que sem uma política pública que estimule essa fonte de energia com a redução de impostos e outros incentivos, ela continuará desprestigiada e marginal.

Ressalta-se a relevância do desenvolvimento de estudos viáveis economicamente e ambientalmente, que sirvam de referencial para profissionais da área de Engenharia, voltados à sustentabilidade ambiental e subsidiar a tomada de decisão por parte de gestores municipais, em especial na implantação de sistema para geração de energia por meio dos resíduos sólidos urbanos.

Assim, o objetivo do estudo foi discorrer a respeito dos efeitos do tratamento de resíduos sólidos e seu impacto na saúde e na economia.

\section{Material e Método}

Estudo de natureza bibliográfica, que tomou como referencial a Política Nacional de Resíduos Sólidos (BRASIL, 2010), a Constituição da República Federativa do Brasil (BRASIL, 1988) e o relatório produzido pela Associação Brasileira de Empresas de Limpeza Pública e Resíduos Especiais (ABRELPE, 2011), no que se refere tanto a problemática da destinação e tratamento dos resíduos sólidos urbanos, como o aparato legal que legitima o direito à população ser assistida com o meio ambiente saudável e sustentável.

A ABRELPE trata-se de instituição pública e sem fins lucrativos. Tem por objetivo principal a preservação do meio ambiente, por meio do desenvolvimento técnico-operacional em conjunto com empresas que realizam limpeza urbana e manejo de resíduos sólidos. Tem vinculação com a Comissão das Nações Unidas sobre Desenvolvimento Sus- tentável (UNCSD).

A questão norteadora foi: quais as consequências da destinação inadequada dos resíduos sólidos urbanos?

O estudo procurou debater a respeito da importância da preservação do meio ambiente e chamar atenção para a implantação de unidades de tratamento de resíduos sólidos, como benefícios à população e o cumprimento da legislação pelo sistema governamental.

\section{Discussão}

É evidente que as necessidades humanas são ilimitadas e o mercado capitalista diariamente oferece novos produtos, com isso o acesso aos bens de consumo leva a geração de resíduo sólido urbano que, se não destinado adequadamente, causa sérios danos ao meio ambiente.

No Brasil, é da responsabilidade do setor público todo o cuidado com os resíduos sólidos, no entanto, há municípios que não atendem o que consta em Lei (Brasil, 1998). Ressalta-se que o crescente acúmulo de resíduos instigou a criação de uma categoria profissional denominada catadores de materiais reutilizáveis e muitos deles trabalham no sistema de cooperativa, onde atuam desde a coleta de materiais até a reciclagem dos mesmos. Ainda assim não é assegurado o equilíbrio ecológico necessário para se ter a sustentabilidade necessária e a precária educação ambiental favorece o surgimento de doenças, principalmente aos profissionais que labutam com os resíduos sólidos.

Portanto, se o sistema governamental não atende as políticas de sustentabilidade do meio ambiente, pode-se considerar que vivemos em crise ambiental, tendo em vista que entre os problemas causados pelos resíduos sólidos estão o aumento de todo tipo de poluição, a exploração das riquezas naturais, o desmatamento, entre outros fatores que promovem o aquecimento global causado pelo efeito estufa (MARCHI, 2015).

Vale destacar que o Decreto $\mathrm{n}^{\circ} 7404$, de 23 de dezembro de 2010, regula a Lei ${ }^{\circ} 12.305$, que instituiu a Política Nacional de Resíduos Sólidos. No entanto, a realidade nos leva a questionar se referida Lei é popularmente conhecida, especialmente no que se refere a:

Art. 6ํㅡㄹ Os consumidores são obrigados, sempre que estabelecido sistema de coleta seletiva pelo plano municipal de gestão integrada de resíduos sólidos ou quando instituídos sistemas de logística reversa na forma do art. 15, a acondicionar adequadamente e de forma diferenciada os resíduos sólidos gerados e a disponibilizar adequadamente os resíduos sólidos reutilizáveis e recicláveis para coleta ou devolução.

A Lei chama atenção para a implementação do plano municipal de gestão integrada de resíduos sólidos e estabelece a responsabilidade do poder público em promover as condições de destinação adequada, como ocorre nas UTR. Porém, cada cidadão deve ter a educação ambiental, visto ser necessário o acondicionamento seletivo de itens reutilizáveis e recicláveis.

No enfrentamento dos problemas ambientais conta-se com os agentes comunitários de saúde, cujo trabalho eminentemente voltado à educação popular, se instruídos podem mudar a realidade de muitas famílias expostas aos danos provocados pelos resíduos sólidos (DUARTE; SOUZA; CLAUDINO, 2011). Pois acreditamos que a crise ambiental 
não desse ser atribuída única e exclusivamente aos gestores. Esses são responsáveis pela implementação de políticas públicas, assim como a população também possui responsabilidade ambiental.

A geração de resíduos sólidos urbanos pode constituir-se em matéria prima para investimentos, no entanto requer não só o cumprimento da Lei pelos gestores, mas a educação ambiental na gestão dos resíduos sólidos por parte da sociedade, considerando-se os valores, comportamentos e estilo de vida relacionados ao meio ambiente sustentável.

Acredita-se que sem o planejamento das ações de saneamento ambiental não há como assegurar a sustentabilidade ecológica.

\section{Conclusão}

Muitas são as consequências da destinação inadequada dos resíduos sólidos urbanos, em especial o desequilíbrio do meio ambiente. $O$ crescente consumo pela população de produtos que geram resíduos sólidos revela o quanto desafiador é a gestão ambiental. A saúde humana depende da sustentabilidade dos recursos naturais como a água e o solo. Nesse sentido as localidades que implantaram as unidades de tratamento de resíduos sólidos não só cumprem com o dever legal, mas promovem a saúde. No entanto, é preciso o despertar para a educação ambiental, que poderia ser induzida nas escolas e nas universidades.

A Política Nacional de Resíduos Sólidos é considerada um importante marco na gestão do meio ambiente, no entanto, seus preceitos não são observados em todos os municípios, haja vista que cidades com mais de 20 mil habitantes devem adotar os procedimentos elencados em Lei, no sentido de propiciar o adequado saneamento ambiental, com isso os impactos positivos na saúde e na economia do setor público.

A limitação do estudo está nas fontes pesquisadas, servindo de referencial para outras pesquisas que possam incluir outras fontes e bases de dados.

\section{Referências}

ASSOCIAÇÃO BRASILEIRA DE LIMPEZA PÚBLICA E RESÍDUOS ESPECIAIS (ABRELPE). Panorama dos resíduos sólidos no Brasil, 2011. Disponível em: <http:// a3p.jbrj.gov.br/pdf/ABRELPE\%20Panorama\%202001\%20 RSU-1.pdf $>$. Acesso em: 20 jan, 2015.

BRASIL, Constituição (1988). Constituição da República Federativa do Brasil. Brasília: Senado Federal: Centro Gráfico, 1988. 292 p.

Lei $\mathrm{n}^{-}$12.305, de 2 de agosto de 2010. Institui a Política Nacional de Resíduos Sólidos, altera a Lei oํ 9.605, de 12 de fevereiro de 1998, e dá outras providências. Diário Oficial [da] República Federativa do Brasil, Brasília, 3 ago. 2010. Seção 3. p. 62.

DUARTE, S. J. H. D.; SOUZA, N. S.; CLAUDINO, T.

$\mathrm{X}$. Relato de experiência acerca do trabalho do agente comunitário de saúde: reflexões sobre sua prática. Rev. Elet

Gestão Saude, v. 2, n. 1, p. 173-183, 2011.
JACOBI, P. R. et al. Mudanças climáticas globais: a resposta da educação. Rev. Bras. Educ. v. 16, n. 46, p. $135-$ $148,2011$.

MARCHI, C. M. D. F. Novas perspectivas na gestão do saneamento: apresentação de um modelo de destinação final de resíduos sólidos urbanos. Rev. Bras. Gest. Urbana, v. 7 , n. 1, p. 91-105, 2015.

VOLOCH, L. Carbonização de resíduo sólido urbano como alternativa de tratamento e geração de energia: viabilidade de aplicação no município de Londrina/PR. 2012. 78 f. Monografia (Trabalho de conclusão de curso em Geografia) - Departamento de Geociências, Universidade Estadual de Londrina, Londrina, 2012.

Recebido: 18/11/2014

Aceito: 20/03/2015 